www.jmscr.igmpublication.org

Impact Factor 5.244

Index Copernicus Value: 5.88

ISSN (e)-2347-176x ISSN (p) 2455-0450

crossref DOI:_http://dx.doi.org/10.18535/jmscr/v4i5.07

Journal Of Medical Science And Clinical Research

\title{
To Study the Effect of Different Phases of Menstrual Cycle on ECG \& Blood Pressure in Healthy Young Adult Females
}

\author{
Authors \\ Shahina Khan ${ }^{1}$, Jai Prakash ${ }^{2}$, Dr Mirza Rashid Ullah Beg ${ }^{3}$, Dr Manoj Kumar \\ Dr Gauhar Hussain ${ }^{5}$, Dr Ranjan Dixit ${ }^{6}$, Shashank S Sinha ${ }^{7}$ \\ ${ }^{1,6}$ Departments of Physiology, Government Medical College, Kannauj \\ ${ }^{2,4,5}$ Department of Physiology, Teerthanker Mahaveer Medical College TMU,Moradabad and \\ ${ }^{3}$ Department of Anatomy, Major S.D. Medical College, Fatehgarh
}

\begin{abstract}
Menstruation coupled periodic bleeding from the blood vessels, at the time of shedding of the uterine mucosa has directed interest, more especially in the ECG changes \& Blood Pressure changes during different phases of menstrual cycle. The aim of the present study was to compare and evaluate the changes in the ECG \& BP measured during different phases of menstrual cycle. Variation in BP during different phases of menstrual cycle can also be attributed to the effect of ovarian hormones on cardiovascular function. Since the hormonal changes follow a non-linear trend throughout the menstrual cycle, it may have unpredicted effect on BP regulation. The present study was carried out on 50 healthy female students aged 17-22 years who had regular menstrual cycle of $30 \pm 3$ days. The electrocardiogram (ECG) recordings were taken on lead II for convenience during the different phases of the menstrual cycle (Phase I-days 1-5, Phase-II-days 9-12, Phase-III-days 1921) in female subjects \& Blood Pressure was analyzed by means of Indirect method during three phases in females. Statistical analysis was done by ONEWAY-ANOVA test. The P wave amplitude, T-wave amplitude, QRS complex amplitude, QRS complex duration, PR interval, ST interval did not show any significant change during different phases of menstrual cycle, although some mild changes were observed which were statistically not significant. QT interval, RR interval has shown significant changes as longer QT interval observed in Phase-II(follicular Phase )\& shorter during Phase-III (Luteal phase).The longer RR interval observed during Phase-III (luteal phase) \& shorter during Phase-I (Menstrual Phase). HR was found higher in Phase-I (menstrual phase) \& lower in Phase-III (luteal phase)in females. They did not show any significant changes in BP measurement taken during three phases. This study was a moderate attempt to determine regular variation in ECG \& BP during the different phases of menstrual cycle in normal healthy females.
\end{abstract}

Keywords: Menstrual Cycle, ECG, Blood Pressure.

\section{Introduction}

Menstruation is a phenomenon which has appeared very late in evolution and is confined to us and our closest cousins, the primates like monkey and apes. In contrast females of subhuman species show oestrous cycle in which sexual activities occur cyclically at a particular time of a year ${ }^{1}$. The cyclical changes that occur in female reproductive system are commonly termed as menstrual cycle. Menstruation is only one manifestation of the ovarian cycle which is itself associated with more than 200 physical, psychological and behavioral changes. The menstrual cycle is an integral part of a major 
portion of a woman's life. The reproductive system of a female, unlike that of a male, shows regular cyclic changes that teleologically may be regarded as periodic preparation for fertilization and pregnancy ${ }^{1}$.

Ovarian hormones alterations along the menstrual cycle are associated with corresponding significant changes in multiple neurohumoral homeostatic mechanisms regulating the cardiovascular system ${ }^{1}$. Gonadal hormones influence the cardiovascular system both directly and indirectly. Ventricular arrhythmias are more common in women and seem to exhibit variation in accordance with the menstrual cycle. There are contradictory hypotheses regarding the influence of the menstrual cycle on different waves, \& intervals of electrocardiogram (ECG). A number of research articles have thrown light into the effects on heart and respiration during menstrual cycle. Some literature shows that the HRV is affected by the menstrual cycle ${ }^{[17,18,]}$. Several studies have found variation of symphatho-vagal activities during the menstrual cycle. Previous studies have indicated parasympathetic activity is lower during the luteal phase compared with other phases of the menstrual cycle in healthy women ${ }^{30}$. Power spectral analysis of heart rate variability has been used as a sensitive index of autonomic nervous activities ${ }^{[30,31,7]}$. Sympathetic activity is significantly higher in the luteal phase than in the follicular phase. However, others have reported the menstrual cycle were not significantly associated with changes in autonomic nervous activity $^{32}$. Repeated cyclical haemorrhages and variations in the oestrogen and progesterone level in the blood during menstrual cycle could affect the blood volume, cardiac activity and may also affect electrocardiographic pattern ${ }^{2}$. The relationship between Menstrual Cycle \& different kinds of arrhythmias have been studied before. This study is an attempt to evaluate the effect of different phases of the menstrual cycle on ECG \& blood pressure in healthy young adult females.

Materials \& Methods
A total of 50 healthy young MBBS female aged 17-22 years(with normal Menstrual Cycle of 30+/3 days, regular for at least 6 months prior to this study)studying in Teerthanker Mahaveer Medical College \& Research Centre, TMU, Moradabad were selected for this study. The females were instructed to come to clinical lab of physiology department during each of three different phases. Day 1-5 during Menstrual phase (PHASE-I), day 9 - 12 during follicular phase (PHASE- II) \& day 19-21 during luteal phase (PHASE-III).The Experiment work was initiated after obtaining approval of the study protocol from the Ethics Committee of Teerthanker Mahaveer Medical College \& Research Centre. The study was carried out in the Department of Physiology, TMMC \& $\mathrm{RC}$, TMU after written informed from the subjects to begin this study.

They were screened for selection on the basis of the following criteria:

- The subject should not have history of any medical illness like Respiratory or Cardiovascular disease.

- The subjects should not have habits of smoking, alcoholism.

- The female subjects should not have Irregular menstrual cycle or Dysmenorrhoea.

- Subjects should not have any history of Hypertension or hypotension and Bradycardia or Tachycardia.

\section{Method}

Basal Parameters were taken to initiate the study. Age, BMI, WHR, Resting Pulse Rate, Resting Blood Pressure were recorded to select the healthy subject for study. Blood Pressure of female subjects were recorded on any one of the day of three consecutive Phases i.e. Phase-I(Day 15),Phase-II(Day9-12),Phase-III(Day 19-21) in supine position by indirect method.ECG were recorded during all three phases in Females i.e. Phase-I (days 1-5), Phase-II (days 9-12), PhaseIII (days 19-21). The ECG was recorded with the help of Lead-II for sake of convenience at a paper 
speed of $25 \mathrm{~mm} / \mathrm{sec}$ and at $1 \mathrm{mV}$ standardization. The subjects were asked to lie comfortably in supine position over a couch. Subjects were instructed to close their eyes and to avoid talking, moving of hands, legs and body, coughing and sleeping during the test. The 4 limb leads Right Arm, Left Arm, Right Foot, Left Foot (RA, LA, $R F, L F)$ were attached to the respective limb of the subject. The ECG was recorded generally in Lead II for the sake of simplicity.

\section{Statistical Analysis}

Statistical analysis was performed using PASW 16.0 (SPSS Inc., Chicago, USA). The data collected (Basal parameters, SBP, DBP, ECG in females) were entered in MS Excel 2010 and analyzed using SPSS. ONEWAY ANOVA (Analysis of variance) was applied to test the difference in mean SBP, mean DBP, Mean values of ECG parameters across three phases. Post-Hoc tests were performed for statistical significance. Statistical significance was set atp $<0.05$.

\section{Results}

In the present study 50 Female medical students of same age group were selected from Teerthanker medical college, TMU, Moradabad. The Basal Parameters are shown in Table $=1$, Figure=I.

Table-I Base-line values (mean \pm SD) of different parameters in female subjects.

\begin{tabular}{|l|l|}
\hline Parameter & FEMALE $(\mathrm{N}=50)$ \\
\hline Age(years) & $18.4 \pm .90$ \\
\hline BMI $\left(\mathrm{Kg} / \mathrm{m}^{2}\right)$ & $20.83 \pm 1.33$ \\
\hline WHR(WC/HC) & $.83 \pm .01$ \\
\hline Resting SBP(mmHg) & $114.68 \pm 4.18$ \\
\hline Resting DBP(mmHg) & $75.16 \pm 3.83$ \\
\hline Resting Pulse Rate (min.) & $74.80 \pm 3.12$ \\
\hline
\end{tabular}

Figure-I Graphical Representation of Mean Values of Basal Parameters in Female .

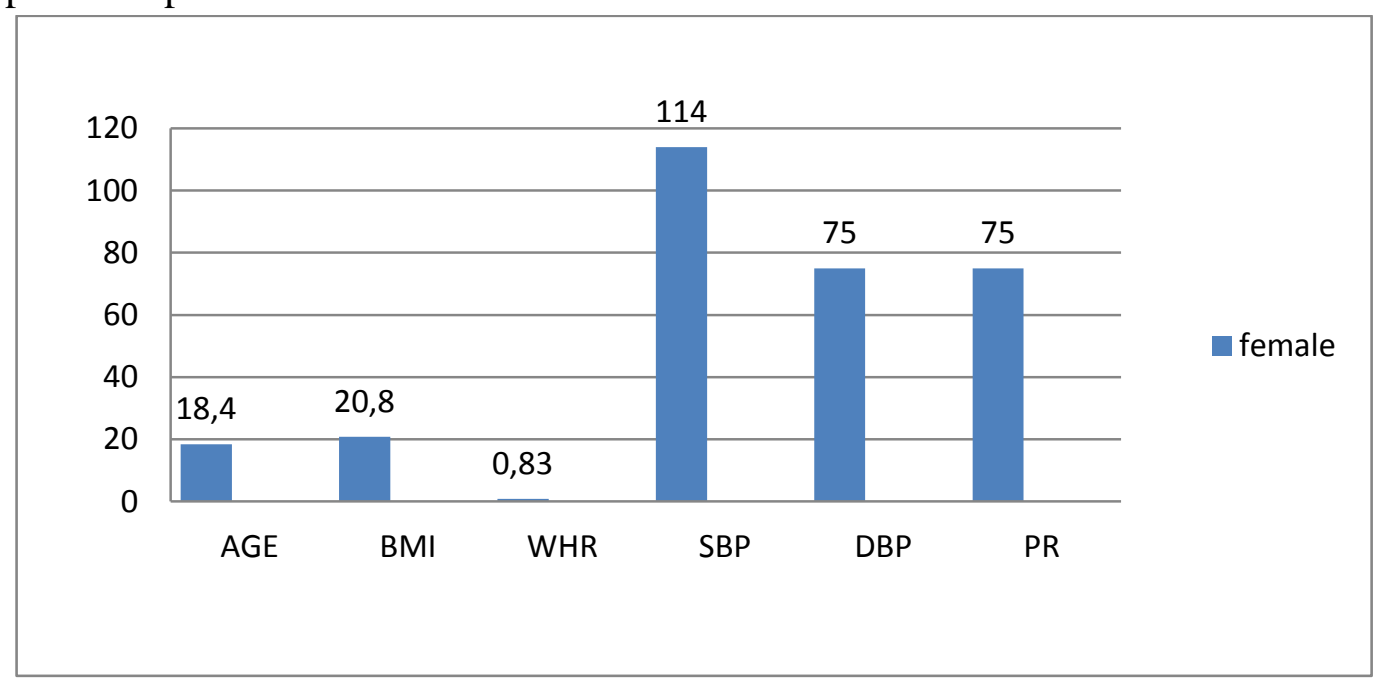

The comparison of Blood Pressure in females during three phases i.e. Phase-I, Phase-II, PhaseIII was done which is shown in Table-2, Oneway Anova descriptive, Figure-2.The Mean SBP was recorded as $108 \mathrm{mmHg}, 108 \mathrm{mmHg}, 110 \mathrm{mmHg}$ in
phases-I,II,III respectively. The Mean DBP was recorded as $69 \mathrm{mmHg}, 69 \mathrm{mmHg}, 72 \mathrm{mmHg}$ in phases-I, II, III respectively.According to our study,differences in the BP parameters during different phases were statistically not significant. 
TABLE-II Blood Pressure Comparison in Three different Phases in Female.

\begin{tabular}{|l|l|l|l|l|l|l|l|l|l|l|l|l|}
\hline Variable & \multicolumn{2}{l}{$\begin{array}{l}\text { Phase-I } \\
\text { (Days 1-5) }\end{array}$} & $\begin{array}{l}\text { Phase-II } \\
\text { (Days 9-12) }\end{array}$ \\
& $\begin{array}{l}\text { Mean } \\
\pm \\
\text { S.D. }\end{array}$ & Max. & Min. & $\begin{array}{l}\text { Mean } \\
\pm \\
\text { S.D. }\end{array}$ & Max & Min & $\begin{array}{l}\text { Mean } \\
\pm \\
\text { S.D. }\end{array}$ & Max 19-21) & Min & IvsII & IvsIII & II vs III \\
\hline $\begin{array}{l}\text { SBP } \\
(\mathrm{mmHg})\end{array}$ & $108 \pm 8.42$ & 126 & 90 & $108 \pm 8.41$ & 130 & 100 & $110 \pm 6.32$ & 126 & 98 & .997 & .287 & .324 \\
\hline $\begin{array}{l}\text { DBP } \\
(\mathrm{mmHg})\end{array}$ & $69 \pm 8.87$ & 90 & 50 & $69 \pm 9.41$ & 100 & 60 & $72 \pm 7.66$ & 88 & 50 & .981 & .274 & .365 \\
\hline
\end{tabular}

significant at $\mathrm{p}<0.05$. (ONEWAY-ANOVA TEST)

PHASE-I:Menstrual phase

PHASE-II:Follicular phase

PHASE-III:Luteal phase

FIGURE-II Graphical Representation of Mean SBP \& Mean DBP (in mmHg) during Three phases in Females

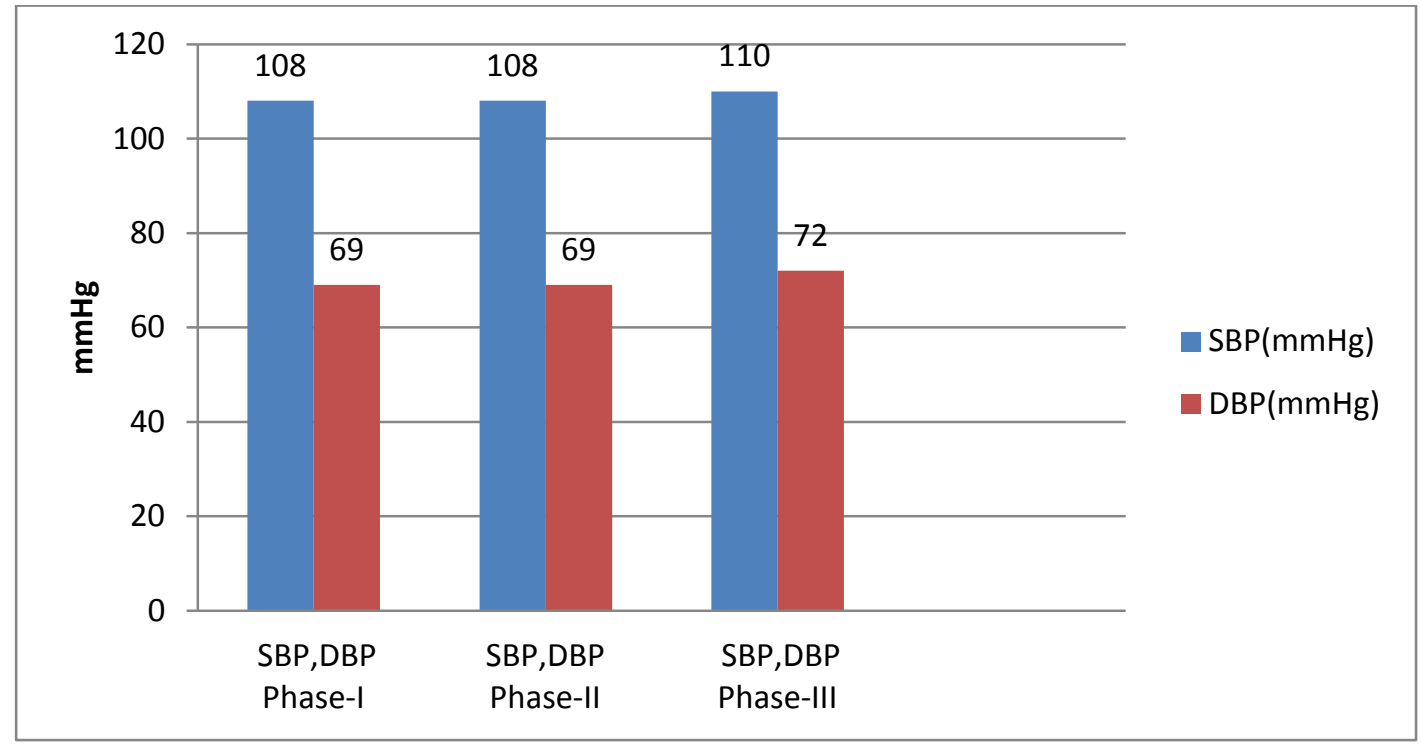

The comparison of ECG Parameters in female subjects was done during three phases i.e. Phase-I, Phase-II, Phase-III, which is shown in Table-III, Oneway Anova descriptive, Figure- III, IV,V. The influence of different phases of menstrual cycle on P-wave amplitude, QRS- complex amplitude, Twave amplitude, QRS-complex Duration, PRInterval, QT-Interval, ST-Interval, RR-Interval \& Heart Rate was studied. The mean values of Pwave observed during three phases were $.22 \mathrm{mv}$, $.23 \mathrm{mv}, .23 \mathrm{mv}$ respectively. The results did not show any statistical significant change in three phases i.e. the amplitude of P-wave almost remained same in all three phases. The Mean values of QRS complex amplitude were recorded as .89mv; .93mv; $.97 \mathrm{mv}$ in phases- I, II, III respectively. In this study the readings were high in phase-III \& low in phase-I .But data did not show any statistical significant difference. The Mean values of $\mathrm{T}$-wave amplitude were recorded as .22mv; .20mv; .19mv in phase- I, II, III respectively. The readings did not show any statistical significant differences between three phases. In the present study the Mean values of QRS complex duration were recorded as .09 sec., .1sec., .1sec in phase I, II, III respectively. The readings did not show any statistical significant difference between three phases. The mean values of PR-interval were recorded as .13 sec., .15sec., $.13 \mathrm{sec}$ in phase I, II, III respectively. The readings did not show any statistical significance. The mean values of ST- interval were recorded as .27 
sec., .27sec., .27sec in phase-I,II,III respectively. The readings did not show any statistical significant difference between three phases. The mean values of QT- interval were recorded as .35 sec., .46sec., .34sec in phase-I, II, III respectively, which was statistically significant. As QT interval was found longer in phase-II \& shorter in phaseIII. The mean values of RR-interval were recorded as .72sec., .76sec., .80sec in Phase-I, II, III respectively i.e. our study showed greater RRInterval in Phase-III (luteal phase) \&lower in Phase-I (menstrual phase). The P-values were significant at $<0.05$ level. The Mean values of HR were calculated as 85 beats/min., 81 beats $/ \mathrm{min}$, 76beats/min. in phase-I, II,III respectively i.e. our studies showed higher HR in Phase-I (Menstrual phase) and lower in Phase-III (luteal phase ). The P-values were significant at $<0.05$ level. (Fig-V).

TABLE-III Comparision of ECG Parameters in Three different Phases(in females)

\begin{tabular}{|c|c|c|c|c|c|c|c|c|c|c|c|c|}
\hline Variables & $\begin{array}{l}\text { Phase-I } \\
\text { (Days 1-5 }\end{array}$ & & & $\begin{array}{l}\text { Phase-II } \\
\text { (Days 9- }\end{array}$ & & & $\begin{array}{l}\text { Phase-III } \\
\text { (Days 19-2 }\end{array}$ & & & P-value & & \\
\hline & $\begin{array}{l}\text { Mean } \\
\pm \\
\text { S.D. }\end{array}$ & Max & Min. & $\begin{array}{l}\text { Mean } \\
\pm \\
\text { S.D. }\end{array}$ & Max. & Min. & $\begin{array}{l}\text { Mean } \\
\pm \\
\text { S.D. }\end{array}$ & Max. & Min. & I vs II & I vs III & II vs III \\
\hline $\begin{array}{l}\text { P-wave amplitude } \\
\text { (mv) }\end{array}$ & $0.22 \pm .04$ & 0.30 & 0.20 & $.23 \pm .04$ & 0.30 & 0.20 & $.23 \pm .04$ & .30 & .20 & .903 & .404 & .667 \\
\hline $\begin{array}{l}\text { QRS-complex } \\
\text { amplitude(mv) }\end{array}$ & $0.89 \pm .24$ & 1.80 & 0.40 & $.93 \pm .27$ & 2.00 & .40 & $.98 \pm .27$ & 1.90 & .60 & .793 & .282 & .655 \\
\hline $\begin{array}{l}\text { QRS-complex } \\
\text { duration (sec.) }\end{array}$ & $.09 \pm .02$ & .16 & .08 & $.10 \pm .02$ & .20 & .08 & $.10 \pm .02$ & .20 & .08 & .275 & .359 & .984 \\
\hline $\begin{array}{l}\text { T-wave amplitude } \\
\text { (mv) }\end{array}$ & $.22 \pm .05$ & .40 & .10 & $.20 \pm .04$ & .30 & .08 & $.20 \pm .05$ & .40 & .10 & .124 & $.023^{*}$ & .767 \\
\hline PR-Interval (sec.) & $.13 \pm .02$ & .20 & .08 & $.15 \pm .04$ & .40 & .12 & $.13 \pm .03$ & .36 & .08 & .067 & .751 & $.010^{*}$ \\
\hline ST-Interval (sec.) & $.27 \pm .02$ & .32 & .24 & $.27 \pm .02$ & .36 & .24 & $.27 \pm .03$ & .36 & .20 & .919 & .989 & .855 \\
\hline QT-Interval (sec.) & $.35 \pm .04$ & .44 & .28 & $.46 \pm .24$ & 1.1 & .32 & $.34 \pm .03$ & .40 & .24 & $.001^{*}$ & .939 & $.000^{*}$ \\
\hline RR-Interval (sec.) & $.72 \pm .07$ & .92 & .60 & $.76 \pm .08$ & 1 & .60 & $.80 \pm .12$ & 1 & .36 & .098 & $.000^{*}$ & .045 \\
\hline HR(beats/min.) & $85 \pm 9.18$ & 100 & 65 & $81 \pm 9.82$ & 100 & 60 & $76 \pm 10.23$ & 100 & 60 & .179 & $.000^{*}$ & $.012^{*}$ \\
\hline
\end{tabular}

*-significant at $\mathrm{p}<0.05$ (ONEWAY-ANOVA TEST). 


\section{JMSCR Vol||04||Issue||05||Page 10406-10414||May}

FIGURE-III Graphical Representation of Mean Values of Amplitude of P-wave, T-wave, QRS complex During different phases in Females (sample size-50).

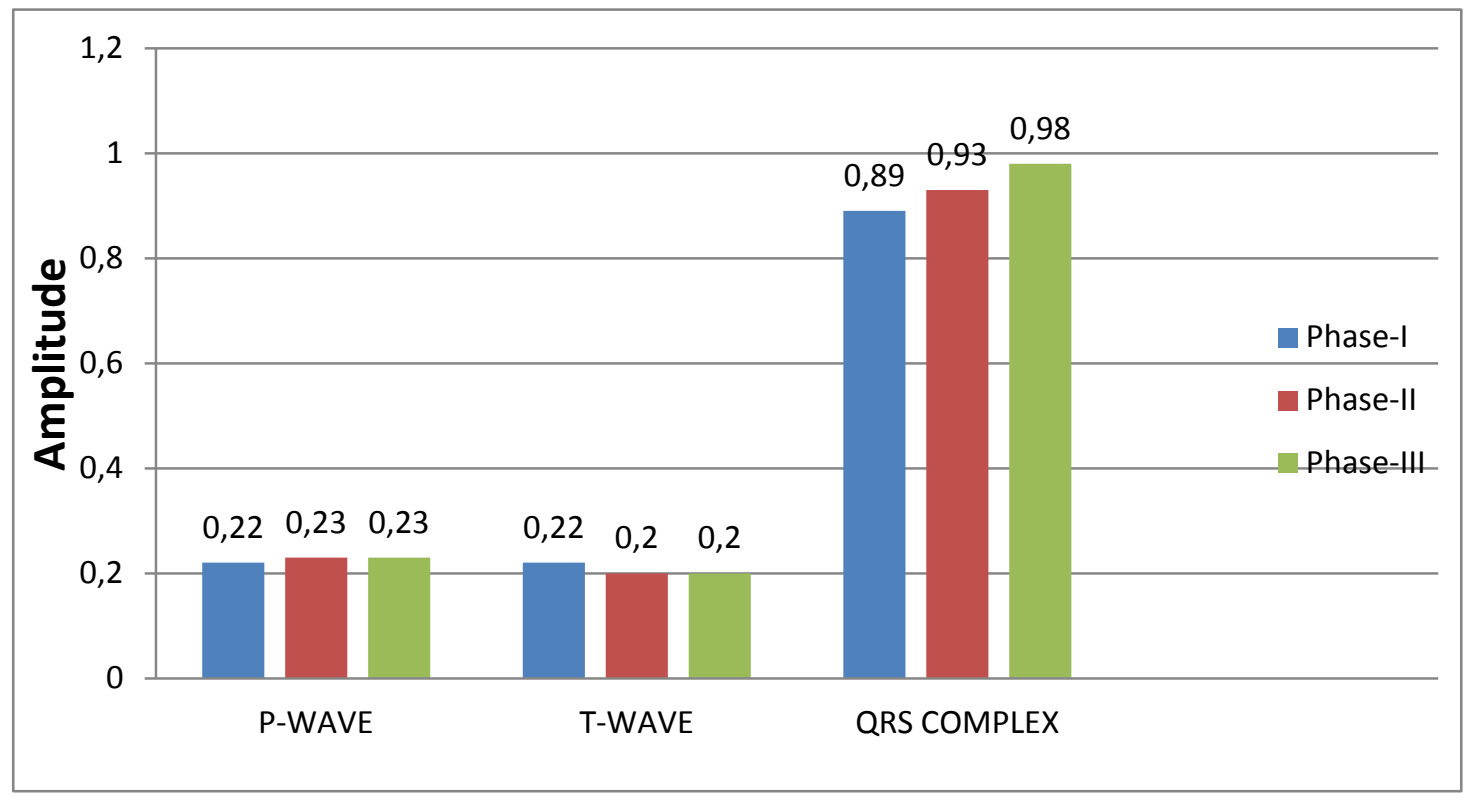

FIGURE-IV Graphical Representation of Mean Values of QRS-complex Duration, PR-Interval, QTInterval, ST-Interval, RR-Interval During different phases in Females.

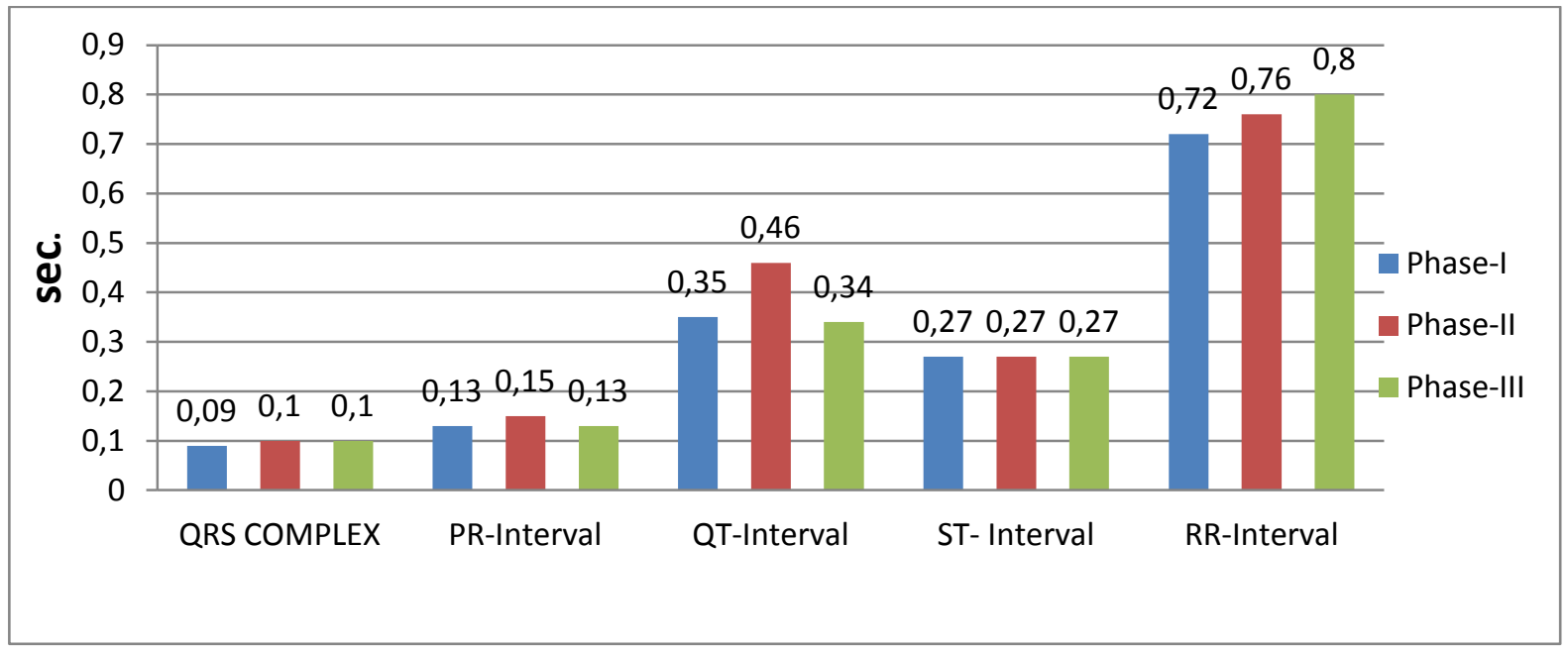

FIGURE-V Graphical Representation of Mean Values of Heart Rate During three phases in Females

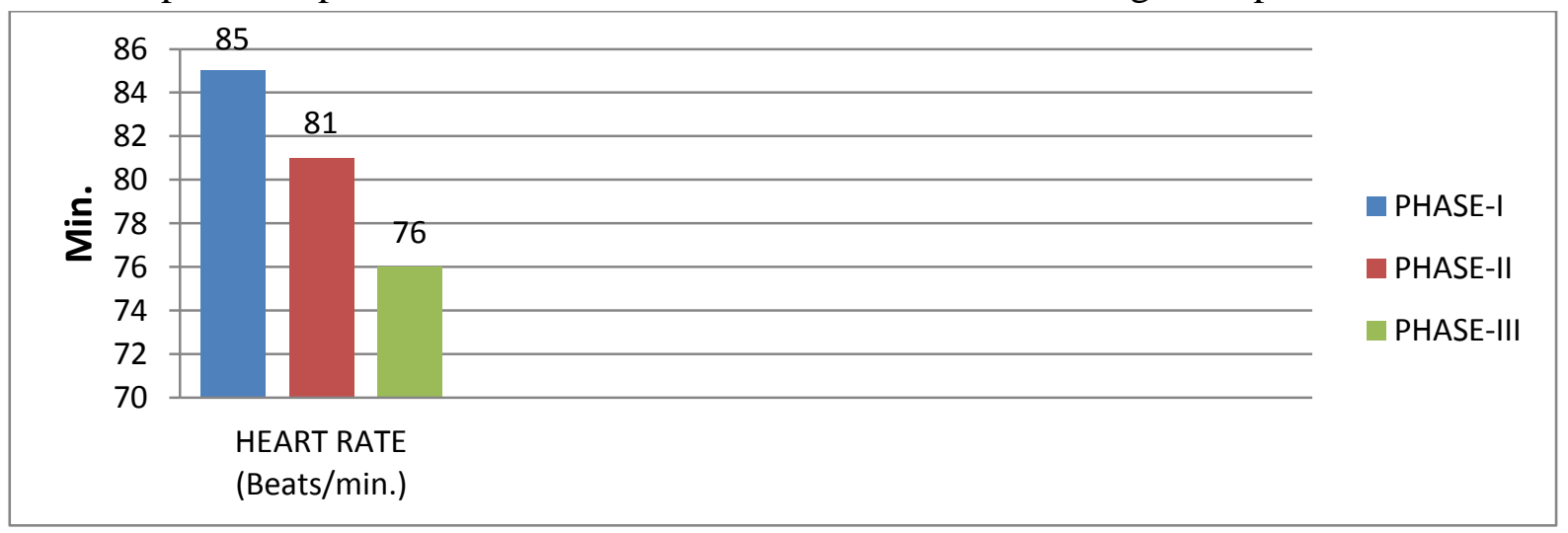




\section{Discussion}

The fluctuation in hormonal concentrations during the menstrual cycle is very well known. The female sex hormones have profound influence on autonomic and metabolic activities. In the present study we examined the "Blood Pressure changes \& ECG changes in three phases of menstrual cycle in healthy young adult females". The influence of the different phases of the menstrual cycle has been studied on factors such as the risk of injury, flexibility, anaerobic power, muscle strength, sports performance, and cardiovascular mechanisms ${ }^{21}$. The general presence of functional sex steroid hormone receptors in the cardiovascular system is well established, their expression in both heart and blood vessels have been recognized for decades. As blood pressure (BP) did not show any significant change during different phases in female subjects, It is suggested that the increase in plasma renin activity, aldosterone, plasma nor-epinephrine and plasma volume in the high hormonal environment during the luteal phase is counter-balanced by a decrease in $\beta 1$ adrenoreceptor sensitivity and an increase in cardiovagal baroreflex activity .These opposite influences of the gonadal hormones result in BP to remain unchanged throughout the menstrual cycle (Hirshoren et al, $2002)^{27}$. A difference of the balance of ovarian hormones may be responsible for these changes of autonomic functions during the menstrual cycle.

The observation of this study was that QT interval was found prolonged during the follicular phase. (.46sec. \pm .24$)$ which is in accordance with earlier studies(Hulot et al 2003, Nakagawa et al 2006, Lokeshwaraiah,2014) in which Mean duration of QT interval was the lowest in the Phase III (luteal phase) when compared to the other two phases, whereas it was most prolonged during the Phase-II (follicular phase) ${ }^{13,14}$. The results of this study, showing prolonged QT interval in the phase-II(follicular phase) of the menstrual cycle show that estrogen has an effect on ventricular action potentials, even within the range of fluctuations seen physiologically in healthy young adults ${ }^{8}$. Others have reported prolongation of QT interval during the luteal phase, may be due to change in serum electrolytes particularly raised levels of sodium. Fluctuations of QT intervals during the menstrual cycle suggest that progesterone may reverse effects of estrogeninduced QT prolongation ${ }^{22}$. The presence of estrogen receptors in the heart, vascular smooth muscle and autonomic brain centres, suggest a possible involvement in the regulation of cardiovascular system ${ }^{20}$. In the follicular phase, estrogen causes an up- regulation in the cardiovascular or myometrial adrenoreceptor ${ }^{3}$.

\section{References}

1. Y.S. Usha Rani, P. Manjunath , R.D. Desai . Comparative Study of Heart Rate variability, Heart Rate \& Blood Pressure in different phases of Menstrual Cycle in healthy young women aged 18-22 years, Journals of Physiology \& Pharmacology advances 2013; 3(7): 188-192.

2. Rajnee,Vinod Kumar Chawla, Raghuveer Choudhary, Bijendra Kumar Binawara, Sunita Choudhary. Haematological \& Electrocardiographic variations during menstrual cycle,Pak J Physiol 2010; $6(1): 18-21$.

3. Vishrutha KV, Harini N, Ganaraja B, Pavanchand A, SusheelaVeliath. A study of Cardiac Autonomic control \& Pulmonary Functions in different phases of Menstrual Cycle, International Journal of Applied Biology \& Pharmaceutical Technology 2012; 3(3): 306-311.

4. Nakagawa M, Ooie T, Takahashi $\mathrm{N}$, Taniguchi $\mathrm{Y}$, Anan F, Yonemochi $\mathrm{H}$, Saikawa $\mathrm{T}$. Influence of Menstrual Cycle on QT interval dynamics, PACE 2006; 29(6): 607-13.

5. Mehnaaz Sameera Arifuddin, Mohammed Abdul Hannan Hazari, Barra Ram Reddy. Blood Pressure Variations during different phases of Menstrual Cycle, IJSN 2012; 3(3):551-554. 
6. Bai X, Li J, Zhou L, Li X. Influence of the menstrual cycle on nonlinear properties of heart rate variability in young women ,Am J Physiol Heart Circ Physiol 2009; 297:765-774.

7. Pomeranz B, Macaulay RJB, Caudill MMA, et al. Assessment of Autonomic Function in humans by Heart Rate spectral analysis. Am J Physiol 1985; 248:H151H153.

8. Edwige Balayssac Siransy, Soualiho Ouattara, AnicetAdoubi, Chantal Kouam, Marie-Laure Hauhouot-Attoungbré, Cyrille Dah Pascal Bogui. Influence of high ovarian hormones on QT-Interval duration in young African women, Physiological Reports by Wiley Periodicals 2014; 2 (3).

9. Sneha B Shetty, Sheila R Pai, Nayanatara AK, Balachandra A Shetty. Comparision of cardiac autonomic activity \& BMI in different phases of Menstrual cycle using Heart Rate Variability, Int J Biomed Adv Res 2011; 2(10): 402-409.

10. Banerjee BK, Sen SC. Electrocardiographic variation manifested during menstruation, J Obstet Gyanecol India 1978; 28:125.

11. Machiko Y, Tsutsumi Y, Furukawa K, Kanno Y, Ryoko M, Satoh H. Influence of normal menstrual cycle on autonomic nervous activity and QT dispersion, Int $\mathbf{J}$ Bioeletromagnatism 2003; 5:152-3.

12. Burke JH, Ehlert FA, Parker MA, Goldberger JJ, Kadish AH. Gender specific differences in the Q-T interval and the effect of autonomic tone and menstrual cycle in healthy adults, Am J Cardiol 1997;79(2):178-81.

13. Hulot JS, Demolis JL, Riviere R, Strabach $S$, Maitre S, Brentano C. Influence of endogenous oestrogens on QT interval duration, Eur Heart J 2003; 24:1663-7.

14. Rajeshwari Lokeshwaraiah, Chitradurga Palaiah Ganashree, Anithu Chandran,
Anjanayya Ramakrishtayya Gorkal. Comparative study of heart rate, QT and QTc intervals during the different phases of the menstrual cycle,Int $\mathbf{J}$ Health Allied Sci 2014; 3(3):154-8.

15. Dimitriev DA, Saperova EV, Dimitriev $\mathrm{AD}$, Karpenko IuD. Features of cardiovascular functioning during different phases of the menstrual cycle,Ross Fiziol Zh Im I M Sechenova2007; 93(3): 300-5.

16. Turgut Karabag, Volkan Hanci, Mustafa Aydin, Sait M. Dogan, Isil O. Turan, Nesligul Yildirin, Naile E. Gudul. Influence of Menstrual Cycle on P-wave dispersion, International Heart Journal 2011;52:23-26.

17. Stoney CM, Owens JF, Mathews KA, et al. Influences of the normal menstrual cycle on physiologic functioning during behavioural stress,Psychophysiology 1990; 2: $125-135$.

18. Weidner G, Helmeg L, et al. Cardiovascular stress reactivity \& mood during the menstrual cycle, Women Health 1990; 6(3): 5- 21.

19. Datta et al. Electro-cardiographic \& serum electrolyte changes during menstrual cycle IJPP 1984;28(2).

20. Mehta V, Chakrabarty AS. Autonomic functions during different phases of menstrual cycle, Indian J Physiol Pharmacol 1993; 37(1):56-8.

21. Sneha B Shetty, Sheila R Pail, Nayanatara Arunkumar, and Balachandra A Shetty. Influence of regular exercise on cardiac autonomic activity in healthy young women during the normal menstrual cycle, RJPBCS 2012; 3(4): 1417-1422.

22. Sneha Shetty, Sheila R Pai, Nayanatara AK, Ramesh Bhat M, Balachandra A Shetty. Comparative study of time \& frequency domain analysis of $\mathrm{HRV}$ in different phases of Menstrual cycle, J Chinese Clin Med 2010; 5(8): 469-473. 
23. Kisan Ravikiran, Mufti Mehak, Kumar Sunil, Deshpande DV.A Study of Influence of Menstrual Cycle on Cardiac Autonomic Function,International Journal of Physiology 2014;2(1):71-74.42.

24. B K Prasad, D V Deshpande, A Sindhuja, H M Kavyashree, Rajashree Patil. QTc Interval: Gender Difference and effect of Menstrual Cycle, IJP 2013; 1(2):91-100.

25. Christina, Kararashah F Kammar, Tambi Medabala, Praveen Patil, Suresh Babu Sayana. A Comparative Study of Cardiovascular Autonomic Function Tests during Different Phases of Menstrual Cycle, International Journal of Health Sciences \& Research 2013; 3(6):34-40.

26. Rautaharju PM. Zhou SH. Wong S, et al. Sex differences in the evolution of the electrocardiographic QT interval with age, Can J Cardiol 1992; 8:690-695.

27. Hirshoren N, Tzoran I, Makrienko I, Edoute Y, Plawner MM, Eldor JI et al. Menstrual cycle effects on the neurohumoral and autonomic nervous systems regulating the cardiovascular system, J Clin Endocrinol Metabol 2002; 87(4):1569-75.

28. Leicht AS, Hirning DA, Allen GD. Heart rate variability and endogenous sex hormones during the menstrual cycle in young women, Exp Physiol 03; 88:441-6.

29. Bhavani T, Ayshwarya S, Suhapriya P, Chandran M \& Sekar babu hariram. Monitoring the Blood Pressure in different phases of menstrual cycle,RJPBCS 2011; 2(2):691.

30. Sayers B Mc A. Analysis of Heart Rate Variability,Ergonomics 1973; 16(1):17-32.

31. Pagani M, Lombardi F, Guzzetti $S$ et al. Power spectral analysis of heart rate and arterial pressure variabilities as a marker of sympathovagal interaction in man and conscious dog. Circ Res1986; 59:178-193.
32. Xiaopeng Bai, Jingxiu Li, Lingqi Zhou, and Xueqi Li. Influence of Menstrual Cycle on nonlinear properties of HRV in young women, Am J Physiol Heart Circ Physiol 2009; 297: H765-H774. 